Article

\title{
Energy Efficiency of Multi-Technology PV Modules under Real Outdoor Conditions-An Experimental Assessment in Ghardaïa, Algeria
}

\author{
Amor Fezzani $^{1}$, Idriss Hadj-Mahammed ${ }^{1}$, Abdellah Kouzou ${ }^{2,3,4, * \mathbb{D}}$, Layachi Zaghba ${ }^{1}$, Said Drid ${ }^{5}$ (D), \\ Messaouda Khennane ${ }^{1}$, Ralph Kennel ${ }^{4}$ and Mohamed Abdelrahem 4,6,*iD
}

1 Unité de Recherche Appliquée en Energies Renouvelables (URAER), Centre de Développement des Energies Renouvelables (CDER), Ghardaia 47133, Algeria; amorfezzani@yahoo.fr (A.F.); hmidriss65@gmail.com (I.H.-M.); layachi40@yahoo.fr (L.Z.); khennane.messaouda@gmail.com (M.K.)

2 Laboratory of Applied Automation and Industrial Diagnostics (LAADI), Faculty of Science and Technology, Ziane Achour University, Djelfa 17000, Algeria

3 Electrical and Electronics Engineering Department, Nisantasi University, Istanbul 34398, Turkey

4 Institute for Electrical Drive Systems and Power Electronics, Technical University of Munich (TUM), 80333 Munich, Germany; ralph.kennel@tum.de

5 Department of Electrical Engineering, University of Batna 2, Batna 05000, Algeria; s.drid@univ-batna2.dz

6 Department of Electrical Engineering, Assiut University, Assiut 71516, Egypt

* Correspondence: kouzouabdellah@ieee.org (A.K.); Mohamed.abdelrahem@tum.de (M.A.)

Citation: Fezzani, A.;

Hadj-Mahammed, I.; Kouzou, A.;

Zaghba, L.; Drid, S.; Khennane, M.;

Kennel, R.; Abdelrahem, M. Energy Efficiency of Multi-Technology PV

Modules under Real Outdoor

Conditions-An Experimental

Assessment in Ghardaïa, Algeria.

Sustainability 2022, 14, 1771. https://

doi.org/10.3390/su14031771

Academic Editor:

Gerardo Maria Mauro

Received: 8 January 2022

Accepted: 1 February 2022

Published: 3 February 2022

Publisher's Note: MDPI stays neutral with regard to jurisdictional claims in published maps and institutional affiliations.

Copyright: (c) 2022 by the authors. Licensee MDPI, Basel, Switzerland. This article is an open access article distributed under the terms and conditions of the Creative Commons Attribution (CC BY) license (https:// creativecommons.org/licenses/by/ $4.0 /)$.

\begin{abstract}
Energy efficiency and ratio performance are two key parameters for the analysis of the performance of photovoltaic (PV) modules. The present paper focusses on the assessment of the efficiency of four different photovoltaic module technologies based on energy efficiency and ratio performance. These PV modules were installed at the Applied Research Unit in Renewable Energy (URAER) in Algeria and were used to provide experimental data to help local and international economical actors with performance enhancement and optimal choice of different technologies subject to arid outdoor conditions. The modules studied in this paper are: two thin-film modules of copper indium selenide (CIS), hetero-junction with intrinsic thin-layer silicon (HIT) and two crystalline silicon modules (polycrystalline (poly-Si), monocrystalline (mono-Si)). These technologies were initially characterized using a DC regulator based on their measured I-V characteristics under the same outdoor climate conditions as the location where the monitoring of the electrical energy produced from each PV module was carried out. The DC regulator allows for extracting the maximum electrical power. At the same time, the measurements of the solar radiation and temperature were obtained from a pyranometer type Kipp \& ZonenTM CMP21 and a Pt-100 temperature sensor (Kipp \& Zonen, Delft, Netherlands). These measurements were performed from July 2020 to June 2021. In this work, the monthly average performance parameters such as energy efficiency are given and analyzed. The average efficiency of the modules over 12 months was evaluated at $4.74 \%, 7.65 \%, 9.13 \%$ and $10.27 \%$ for the HIT, CIS, mono-Si and poly-Si modules, respectively. The calculated percentage deviations in the efficiency of the modules were $8.49 \%, 18.88 \%, 19.74 \%$ and $23.57 \%$ for the HIT, CIS, mono-Si and poly-Si modules, respectively. The low variation in the efficiency of the HIT module can be attributed to the better operation of this module under arid outdoor conditions, which makes it a promising module for adaptation to the region concerned.
\end{abstract}

Keywords: multi-technology PV; module temperature; energy efficiency; efficiency percentage deviation; ratio performance

\section{Introduction}

The political, economic and energy situation in Algeria is currently favorable to the integration of renewable energy into the existing national power system. Solar energy, photovoltaic (PV) in particular, is of major interest in boosting the national renewable 
energy and energy efficiency transition program which was launched by the Algerian government in 2011 [1]. The renewable energy program was improved and updated in 2021, and it aims toward the concretization of the installation of total renewable energy capacity of $16 \mathrm{GW}$ by 2035 , based on solar PV, of which a first tranche of $4000 \mathrm{MW}$ is to enter production by 2024. It is well known that the photovoltaic power plants are suitable for small-scale electricity generation, and several power plants have been installed and connected to the grid in several sites in the country characterized by different types of climate (temperate, semi-arid, arid, desert, etc.). In total, 21 photovoltaic power plants have been in service since 2014. Indeed, the photovoltaic module technology is useful for the purpose of directly converting solar irradiation into electricity where there are various PV modules of different semiconductor materials which can be used for power electricity generation, such as monocrystalline (mono-Si) and polycrystalline (poly-Si) silicon, gallium arsenide (GaAs), cadmium telluride ( $\mathrm{CdTe})$, hetero-junction with intrinsic thin-layer silicon (HIT), triple-junction solar cells composed of indium gallium phosphide (InGaP) - these are among the main materials used for PV modules [2,3]. Kumar et al. [4] presented a review study on different solar photovoltaic technologies and mathematical modeling to characterize the PV systems in which performance analysis was based in terms of standard parameters such as yield energy, reference energy, capacity utilization factor and ratio performance, and based on exergy as well as energy efficiency. Their analyses show that weather conditions, degradation and failure modes are significant for the accurate prediction of photovoltaic systems' performance.

The manufacturers certified their fabricated PV modules under standard test conditions (STC), namely $1000 \mathrm{~W} / \mathrm{m}^{2}, 25^{\circ} \mathrm{C}$, AM 1.5 and wind speed less than $5 \mathrm{~m} / \mathrm{s}$ ), prior to their outdoor exposure. However, the PV modules are intended to operate under real climatic conditions related to the installation site $[3,5]$.

Therefore, the performance and efficiency of the PV modules change according to site-specific environmental parameters such as radiation intensity, module temperature [6], relative humidity [7], dust [8], aged PV module [9], cell spacing [10] and in terms of financial analysis PV [11], etc.

Indeed, evaluation of real weather conditions is very important for the long-term behavior quantification of PV modules based on defining the best module technology suitable for a specific location. Recently, several investigations have been developed in the literature on the study of the influence of real onsite outdoor environment conditions on PV modules of different semiconductor technologies.

Carr et al. [12] compared five different technologies of PV modules based on annual and monthly assessments of their performances, namely crystalline silicon (mono-Si), laser grooved buried contact (LGBC) mono-Si, polycrystalline (poly-Si), triple-junction amorphous ( $3 \mathrm{j} \mathrm{a-Si}$ ) and copper indium diselenide (CIS), which were exposed to a temperature climate in the range of $16.5-28{ }^{\circ} \mathrm{C}$ at a specific site in Perth, Western Australia. They found that the thin-film modules, namely the triple-junction amorphous and copper indium diselenide modules, produced more energy compared to mono-Si modules, with an increase of $8 \%$ and $9 \%$ in winter, and $15 \%$ and $13 \%$ in summer, respectively. In India, Sharma et al. [13] presented a performance assessment of three PV technology arrays at specific site, namely polycrystalline (poly-Si), hetero-junction with intrinsic thin-layer silicon (HIT) and amorphous single-junction silicon (a-Si), which were examined under the same real external climatic conditions based on the annual values of their energy efficiency and performance ratio. The authors noticed that the HIT and a-Si arrays performed better than the poly-Si array. Cañete et al. [14] carried out a comparative study based on energy performance among four (04) different PV module technologies, namely amorphous silicon (a-Si), tandem structure of amorphous silicon, cadmium telluride (CdTe) and microcrystalline silicon (a-Si/ $\mu \mathrm{c}-\mathrm{Si})$, which were installed and exposed to the same climatic conditions in a specific region of Southern Spain. The results obtained showed that the daily efficiency decreased with respect to the efficiency under standard test conditions (STC) given by the manufacture by $5.0 \%, 5.4 \%, 6.5 \%$ and $7.6 \%$ for a-Si, CdTe, a-Si $/ \mu \mathrm{c}-\mathrm{Si}$ and poly-Si modules, 
respectively. Başoğlu et al. [15] presented an energy performance analysis of three different PV array technologies, namely monocrystalline silicon (mono-Si), polycrystalline (poly-Si) and cadmium-telluride (CdTe), which were installed in an on-gird application in Izmit, Northwest Turkey, and monitored for over 14 months. The authors found that due to the low dependency on climatic changes, the mean array efficiencies (MAEs) of CdTe resulted in higher values than the other arrays. Elibol et al. [16] analyzed three different technologies, namely monocrystalline (mono-Si), polycrystalline (poly-Si), and amorphous silicon (a-Si), in Northwest Turkey based on a statistical analysis with the aim of establishing the relationship between the performance ratio and the efficiency of the studied array technologies. It was found that with a temperature increase of $1^{\circ} \mathrm{C}$, the efficiency of the poly-Si arrays and a-Si arrays increased by $0.033 \%$ and $0.029 \%$, respectively, while the efficiency of the mono-Si array decreased by $0.084 \%$. Gaglia et al. [17] examined the energy efficiency of a small polycrystalline PV array under real onsite outdoor conditions in Greece. The efficiency they obtained was 18\% lower than that which was obtained under STC, which was stipulated by the manufacturer. Tahri et al. [18] reported an evaluation of the performance of four (04) grid-tied PV systems under tropical climate conditions in Japan, namely two PV systems based on polycrystalline (poly-Si) and two PV systems using thin-film technology of copper indium selenium (CIS); these were monitored for one year. It was observed that the efficiencies of the PV systems with polycrystalline modules were better than those with CIS in all seasons except in the winter. Kafui et al. [19] presented a study comparing efficiency among five PV modules of different technologies, namely monocrystalline silicon, polycrystalline silicon, transparent monocrystalline silicon and amorphous silicon, all subject to the same outdoor conditions in Hungary. The experimental results obtained onsite show that the higher value deviation was obtained for the polycrystalline PV module, while the minimum value deviation was recorded for the monocrystalline PV module. Gulkowski et al. have presented a comparative analysis between three types of grid-connected PV systems subject to temperate climate conditions in Eastern of Poland [20]. These systems were composed of modules based on three technologies, namely thin film (cadmium-telluride (CdTe)), copper indium gallium selenium (CIGS) and polycrystalline (poly-Si) modules. The experimental results obtained show that the efficiency decreased according to the efficiency measured under standard test conditions (STC) given by the manufacturer. Adouane et al. [21] presented a comparative performance evaluation of eight different PV modules based on the technologies of mono-Si, poly-Si, HIT and thin film (CdTe, CIGS, and a-Si) under outdoor conditions in Kuwait, which were monitored for 12 months. They found that the mono-Si, poly-Si and HIT modules performed better at high irradiance levels, while their performances decreased suddenly at a lower irradiance. The amorphous module, by contrast, showed good performance at low irradiance due to its better light-absorbing characteristics.

Indeed, recently several research works on the performance of multi-technology PV were conducted in some regions of Algeria under different climate conditions. Guenounou et al. [22] analyzed the performance of four (04) different PV panels of different technologies, namely monocrystalline (mono-Si), polycrystalline (poly-Si), amorphous silicon (a-Si) and micro-morph silicon $(\mu-S i)$, which were installed in a region near the southern shore of the Mediterranean Sea in Algeria. Their analyses show that the a-Si and $\mu$-Si panels ensured better performance ratios in summer, contrary to the monocrystalline and polycrystalline panels, which ensured better performance ratios in winter. In 2017, Balaska et al. [23] conducted a performance evaluation of five different PV module technologies under outdoor conditions in the region of Saida, Algeria. The module technologies investigated were three thin-film modules (tandem structure of amorphous silicon and microcrystalline silicon (a-Si_Mc-Si), mono-crystalline hetero-junction with intrinsic thin-layer (HIT) and copper indium selenide (CIS)) and two crystalline silicon modules (mono-crystalline back contact and multi-crystalline). The authors observed that the daily PV efficiency and output power of all the modules depended on the daily irradiance received on the plane of the module and the module temperature. Chikh et al. presented a performance assessment 
of a grid-connected PV plant under arid climate conditions. This plant was composed of four (04) PV technology sub-systems, namely monocrystalline (mono-Si), polycrystalline (poly-Si), thin-film cadmium-telluride (CdTe) and amorphous silicon (a-Si), monitored for one year [24]. The authors found that thin-film PV sub-systems (a-Si, CdTe) performed better than crystalline silicon (mono-Si, poly-Si) PV sub-systems.

The study presented in this paper is based on the real measurements collected on the site of the test bench after three years of its operation, which were installed at the Applied Research Unit for Renewable Energies (URAER) of Ghardaïa in the southern region of Algeria. The main aim was the assessment of the performance of the various installed PV technology modules under real outdoor climatic conditions. The main contribution in this study can be summarized as follows:

- Presentation of the collected measurements of the real maximum power produced from the four multi-technology modules PV installed on the experimental photovoltaic platform at the URAER in Algeria from July 2020 to June 2021.

- Performance analysis of the multi-technology PV modules exposed to the same climatic conditions.

- Evaluation of the percentage deviation of the energy efficiency and ratio performance of the PV module technologies under study based on the stipulated date by the manufacturer in case of application under the typical weather conditions of Ghardaïa, Algeria.

Furthermore, most of the published papers dealing with the performance of PV multitechnology modules under different climate conditions in Algeria did not provide the percentage deviation on the energy efficiency of the photovoltaic modules under outdoor climatic conditions. It is worthy to mention that the other PV technologies presented in this work were not covered in the above previous studies at the same site as the present study, which allows for providing experiment data to help local and international economical actors to improve the performance of the four (04) different technologies under arid outdoor weather, which is mainly characterized by dry weather.

The investigation presented is based on the energy efficiency of multi-technology PV modules, namely mono-Si, poly-Si, CIS and HIT. The study was carried out during one year under the same outdoor conditions during the period from July 2020 to June 2021 at the site of Ghardaïa, Algeria. The main goal of this investigation was to find the PV technology which performs better under the climate of the site studied, based on a comparison of the real-time measured PV energy efficiency under real outdoor operating conditions obtained under standard test conditions (STC) stipulated by the manufacture.

The rest of this paper is organized as follows:

Section 2 describes the methods used for the outdoor measurement and the mathematical analytical calculation. Section 3 presents the measurement and analysis of the experimental data obtained based on outdoor testing. The main outcomes of the study are presented in Section 4. This paper ends with a conclusion.

\section{Materials and Methods}

\subsection{Outdoor Measurements}

The experimental test bench was installed within the Applied Research Unit in Renewable Energy (URAER) of Ghardaïa in southern Algeria $\left(32^{\circ} 34^{\prime} \mathrm{N}, 3^{\circ} 41^{\prime} 55^{\prime \prime} \mathrm{E}\right), 15 \mathrm{~km}$ from the center of the Ghardaïa downtown. This region is characterized by a dry and hot climate in summer and a cold climate in winter. The maximum solar radiation varied between 800 and $1100 \mathrm{~W} / \mathrm{m}^{2}$ in terms of the modules. The temperature varied between $-5^{\circ} \mathrm{C}$ and $50^{\circ} \mathrm{C}$. Indeed, the site concerned in this study is usually subject to severe climatic conditions, which allowed for a good evaluation of the performance of the solar equipment [25]. The test strip consisted of the following elements:

- Four types of PV modules of different technologies: monocrystalline silicon (mono$\mathrm{Si})$, polycrystalline (poly-Si), copper indium selenium (CIS) and hetero-junction with intrinsic thin-layer silicon (HIT), which were installed and tested on an experimental 
photovoltaic platform within the URAER (Figure 1). The main standard electrical characteristics of the modules given by the manufacturer relating to each module are presented in Table 1. The supporting structures of the modules were fixed and inclined towards to south at the latitude of the place (the inclination angle is $\theta=32^{\circ}$ ).

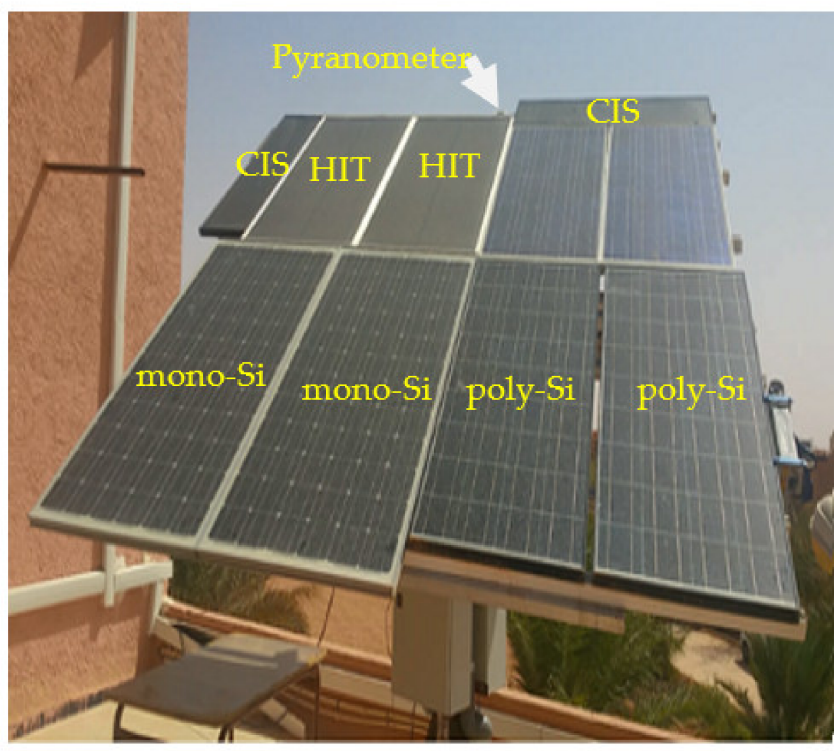

(a)

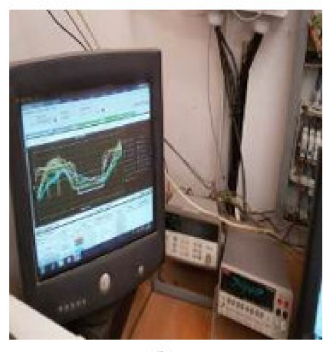

(b)

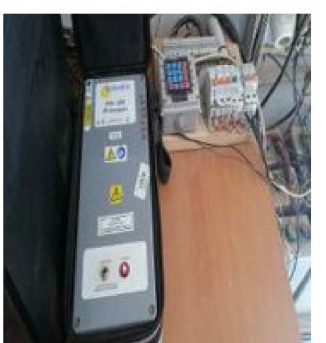

(c)

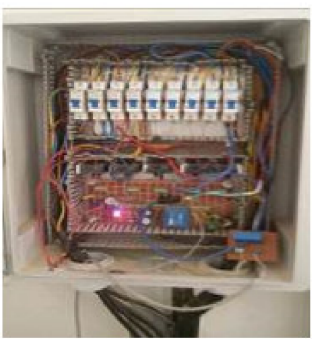

(d)

Figure 1. Experimental test bench (URAER). (a) Platform containing the photovoltaic modules with temperature and solar radiation sensors; (b) Data acquisition device and PC; (c) Electronic load; (d) Connection cabinet.

Table 1. Standard electrical characteristics of the modules.

\begin{tabular}{ccccc}
\hline PV Technology & mono-Si & poly-Si & CIS & HIT(3J: a-Si) \\
\hline Manufacturer & ATERSA & Kyocera & Shell ST 40 & UNI-SOLA \\
\hline Country & Spain & Japan & Netherlands & Mexico \\
\hline Power maximum $P_{\mathrm{mpp}}(\mathrm{W})$ & 150 & 125 & 40 & 64 \\
Module efficiency $\eta(\%)$ & 11.4 & 13.45 & 9.43 & 5.18 \\
Photovoltaic area of a module S $\left(\mathrm{m}^{2}\right)$ & 1.3162 & 0.9291 & 0.42104 & 1.2354 \\
Temperature coefficient of $\gamma \mathrm{P}_{\mathrm{mpp}}\left(\% /{ }^{\circ} \mathrm{C}\right)$ & -0.4 & -0.42 & -0.41 & -0.45 \\
\hline
\end{tabular}

- A pyranometer type Kipp \& Zonen ${ }^{\mathrm{TM}} \mathrm{CMP} 21$ (sensitivity $18.58 \mu \mathrm{V} / \mathrm{W} / \mathrm{m}^{2}$, maximum operational irradiance $4000 \mathrm{~W} / \mathrm{m}^{2}$ and operating temperature range $-40{ }^{\circ} \mathrm{C}$ to $+80^{\circ} \mathrm{C}$ ) was installed on the same plane as the modules.

- A Pt-100 type temperature sensor $\left( \pm 0.3^{\circ} \mathrm{C}\right)$ was fixed to the rear face of each PV module. 
These modules were exposed to the same conditions onsite with a cleaning once a month on average. On the other side, a battery charge controller based on the MPPT algorithm was used to ensure the control of the produced energy from each PV module under study, which allowed for extracting the maximum power from the module to be injected into the battery storage system. The collection of the measured data from the modules, such as the temperatures, solar radiation, currents and voltages, was ensured by using an Agilent 34970A (Agilent technologies Inc. Lovelend manufacturing Center, Colorado, USA) type data acquisition device, whose main technical characteristics are presented in Table 2.

Table 2. Technical characteristics of the data acquisition system.

\begin{tabular}{cccc}
\hline Parameters Measured & Voltage Range & Current Range & Frequency Band \\
\hline Voltage (V) & $0-300$ & - & $3(\mathrm{~Hz})-300(\mathrm{kHz})$ \\
Current (A) & - & $0-1$ & $3(\mathrm{~Hz})-5(\mathrm{kHz})$ \\
\hline
\end{tabular}

This acquisition device operation was based on the use of the Agilent Benchlink Data Logger software, which allows specifying the channels, the measurement range and the data acquisition sampling time. The Agilent device 34970A used was connected to a computer on which the Benchlink Agilent Data Logger software version 1.0 (www.keysigh.com) was installed to ensure the success of real-time measurement and continuous storage of the collected data.

\subsection{Performance Analysis of the PV Modules}

The performance of each PV panel among the study technologies was analyzed using the technical indicators based on the evaluable date collected onsite, such as the performance indicators developed by the International Energy Agency (IEA) within the Photovoltaic Power Systems Program, which were established initially by the IEC standard 61,724 [26-28]. In this section, the definitions of the main indicators used in this paper for the performance analysis of the PV panels are presented in detail.

\subsubsection{Energy Output $\mathrm{E}_{\mathrm{DC}}$}

The total energy produced is the sum of the power measured by the module under real outdoor conditions during the measurement sampling period $(\tau)$, which is expressed as follows:

$$
E_{D C}=\tau \sum_{i=1}^{N} P_{m e s, i}
$$

where $\tau$ is the sampling time of the measurements $(4 \mathrm{~min}) ; P_{\text {mes, }}$ is the maximum power measured at interval of time " $i$ " $(\mathrm{kW})$ and $N$ is the number of equal intervals of time $\tau$ measured.

\subsubsection{PV Module Efficiency Hreal}

The efficiency of the photovoltaic module is the ratio between the energy produced by the PV module and the solar incident radiation on the overall surface of the PV module studied. It can be expressed as follows:

$$
\eta_{\text {real }}=\frac{E_{D C}}{G \times S}
$$

where $E D C$ is the output energy of the PV module, $G$ is the global solar radiation incident on the surface of the module $\left(\mathrm{W} / \mathrm{m}^{2}\right)$ and $S$ is the total surface of the module $\left(\mathrm{m}^{2}\right)$. 


\subsubsection{Efficiency Percentage Deviation}

This indicator presents the percentage deviation of PV module efficiency under actual site conditions, which is defined as:

$$
\Delta \eta=\frac{\eta_{S T C}-\eta_{\text {real }}}{\eta_{S T C}} \times 100
$$

where Hreal is the conversion efficiency calculated onsite and HSTC is the standard nominal efficiency, which is normally stipulated by the manufacturer.

\subsubsection{Performance Ratio Efficiency (PR_Hpv)}

The performance ratio is defined as the ratio of the efficiency of the PV module during its operation onsite to the efficiency at STC of the same module, which can be defined as follows [28,29]:

$$
P R \_\eta=\frac{\eta_{\text {real }}}{\eta_{S T C}}
$$

\section{Results and Discussion}

The study presented in this paper mainly deals with the presentation and analysis of the measured data collected onsite for four different PV technologies during the period of monitoring. These technologies were the thin-film module of copper indium selenide (CIS), the hetero-junction with intrinsic thin-layer silicon (HIT) and the crystalline silicon modules (polycrystalline (poly-Si) and monocrystalline (mono-Si)). These PV modules under study were fixed and inclined towards to the south with an inclination angle of $\theta=32^{\circ}$ on the site concerned. Indeed, the present analysis was carried out based on certain measurements such as the daily average solar radiation, the monthly average air temperature, the monthly average module temperature, the monthly average energy efficiency and the performance ratio. Figure 2 shows the daily solar radiation on the module plane and the air temperature during the period from July 2020 to June 2021. It can be observed that the daily average solar radiation varied between $5.16 \mathrm{~kW} / \mathrm{m}^{2}$ and $6.92 \mathrm{~kW} / \mathrm{m}^{2}$ for January and August, respectively. By contrast, the highest monthly average air temperature value $\left(38.2{ }^{\circ} \mathrm{C}\right)$ was registered in August and the minimum value $\left(16.37^{\circ} \mathrm{C}\right)$ was measured in December.

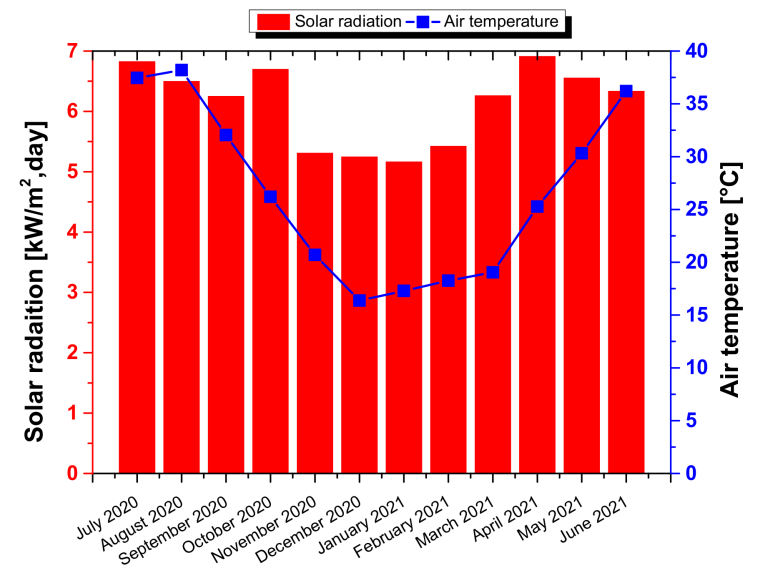

Figure 2. Monthly averages of solar radiation and air temperature in Ghardaïa.

Figure 3 shows the monthly average temperatures for each PV module. It can be clearly observed that the lowest monthly average temperature was measured in December and the highest in August for all modules. It is obvious that the CIS module had the highest monthly average temperature throughout the year compared to the other modules studied. 


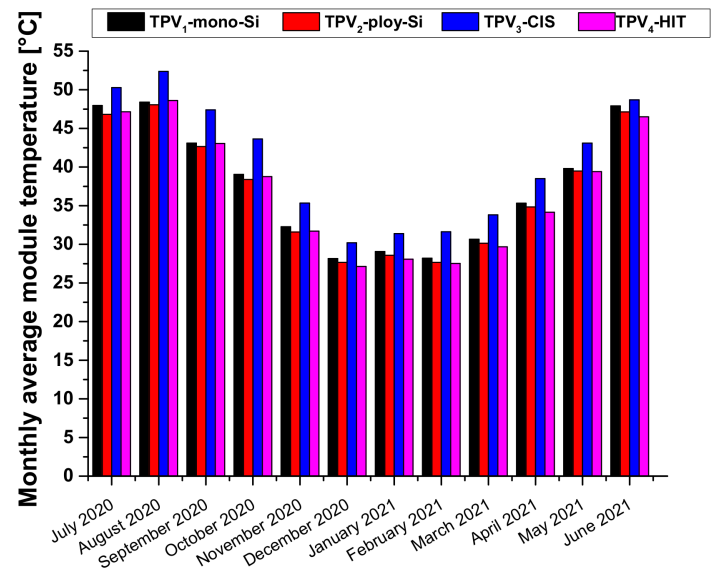

Figure 3. Monthly averages of module temperatures for each PV module.

Figure 4 shows the temperature variation of the modules studied versus the solar radiation. It is clear that the real measured values could not reach those which could be obtained under standard test conditions onsite.
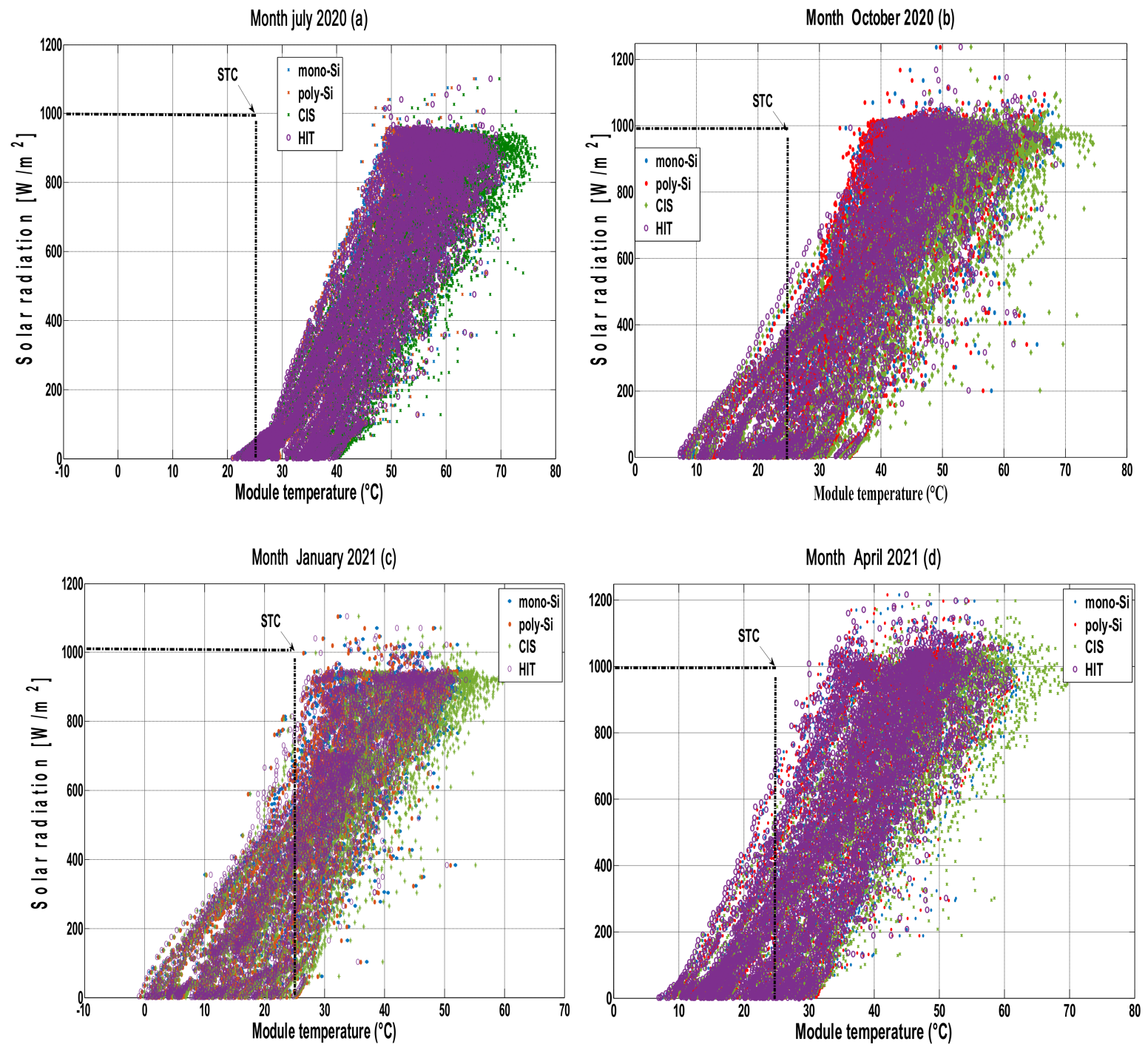

Figure 4. Variation in module temperatures with solar radiation during the months of (a) July 2020, (b) October 2020, (c) January 2021, (d) April 2021. 
It is well known that the average efficiency of the photovoltaic module presents the main characteristic on which the evaluation of its performance is based. It is usually given under STC and nominal operation conditions (NOCT) in datasheets of the manufactures and it is directly related to the technology of the photovoltaic module used.

The efficiency was calculated using Equation (2). The results obtained for this parameter of the PV modules tested are given in the histogram shown in Figure 5.

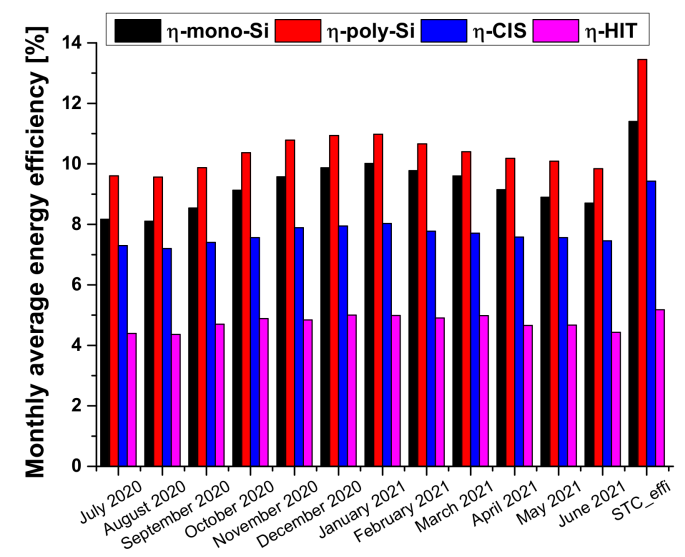

Figure 5. Monthly energy efficiency of the PV modules tested.

Typically, the efficiency of the PV modules varied from one month to another throughout the seasons and the year. It was observed that the modules had maximum values in winter and minimum values during the months with higher temperatures, which means that the module temperature increased again from autumn to winter. The efficiency of the different technologies of the studied modules varied following this rule between maximum values and minimum values: for the HIT it varied between the values of $4.36 \%$ in August and $5.00 \%$ in January, for the CIS between $8.03 \%$ in January and $7.20 \%$ in August, for the mono-Si between $10.01 \%$ in January and 8.10\% in August, for the poly-Si between $10.98 \%$ in January and $9.56 \%$ in August. The conversion energy efficiencies indicated high values for the silicon-based modules (poly-Si and mono-Si) and lower energy efficiencies for the other module technologies. It is worthy to note that all PV module technologies had their highest energy efficiency during the winter seasons due to the lower air temperature in comparison with summer.

Figure 6 shows the deviation of the measured efficiency of the technologies studied from the efficiency obtained under STC. The maximum deviations for the four (04) cases were $0.82 \%, 2.23 \%, 3.3 \%$ and $3.89 \%$ for HIT, CIS, mono-Si and poly-Si, respectively. It can be concluded that the real efficiencies of the modules were generally lower than those obtained under STC. The lowest monthly efficiency deviation based on STC can be observed within the HIT module during the period of monitoring, as shown in Figure 6. Under important changes in real outdoor conditions, the low deviations in the energy efficiency were an observable feature of the PV modules [15].

Figure 7 demonstrates the experimental yearly average efficiency of each PV technology during the testing period. The calculated average efficiency of the four technologies were $4.74 \%, 7.65 \%, 9.13 \%$ and $10.27 \%$ for the HIT module, the CIS module, the mono-Si module and the poly-Si module, respectively. Based on these results, it can be said that this parameter is directly related to the technology of the module. A comparison between the standard nominal efficiencies provided by the manufacturer for the four (04) technologies and the values calculated based on the onsite measurements show a significant difference in this parameter, as shown in Figure 7. The experimental results show that the efficiency decreased when compared to the efficiency under standard test conditions (STC) provided by the manufacturer, and that this difference was essentially related to the PV module temperature increase which led to the increase in the energy losses. 


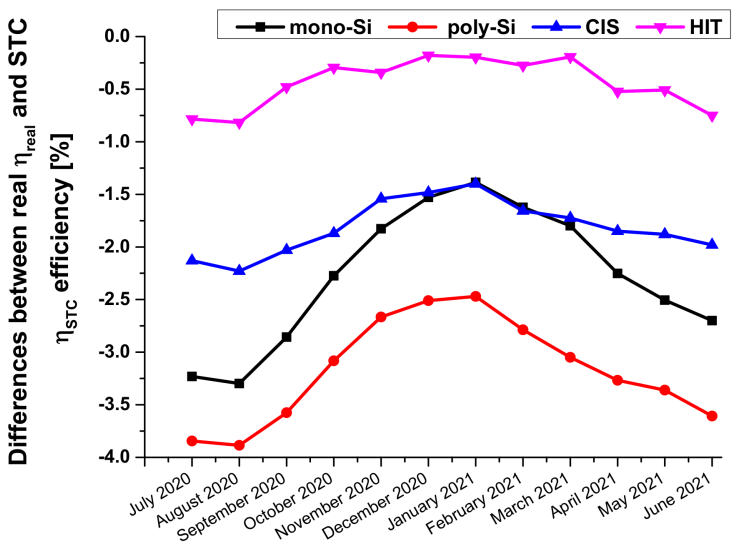

Figure 6. Difference between measured energy efficiency and STC efficiency for each PV module technology.

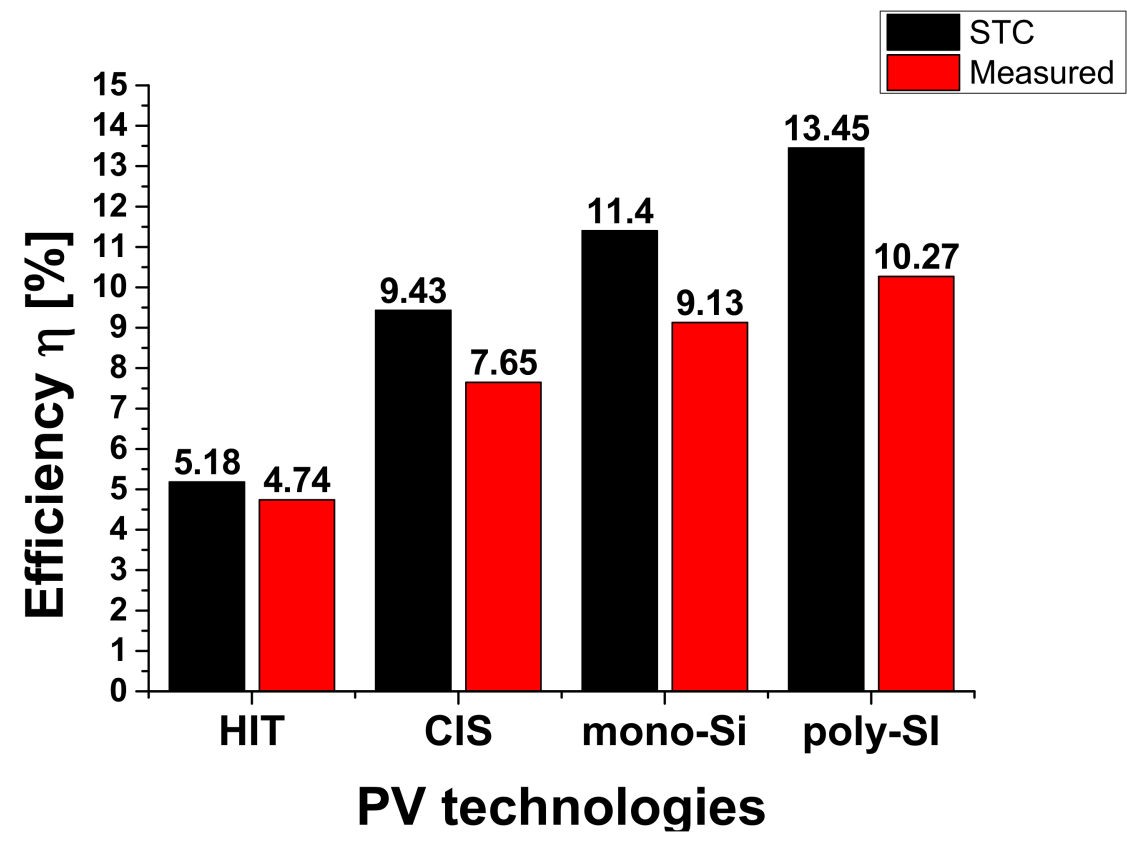

Figure 7. Standard energy efficiency obtained experimentally for the PV modules tested.

The efficiency percentage deviations of each PV module technology are depicted in Figure 8 . Their calculated values were $8.49 \%, 18.88 \%, 19.74 \%$ and $23.57 \%$ for the HIT, CIS, mono-Si and poly-Si modules, respectively. It is clear that the highest percentage deviation value was obtained in the case of polycrystalline technology. On the other hand, the HIT module had the lowest value of $8.49 \%$, which demonstrates the good operation behavior of this module technology under the severe temperature conditions of the site under investigation. At the same time, the anticipated impact on each module's performance according to the relevant parameters was associated with the reception of the solar radiation by the PV modules (G, AM, dependence of absorption and transmittance). It can also be observed that the temperature was the parameter that had the most significant impact on the PV efficiency, and that consequently it contributed highly to the deviation of the efficiency from its rated value [17]. 


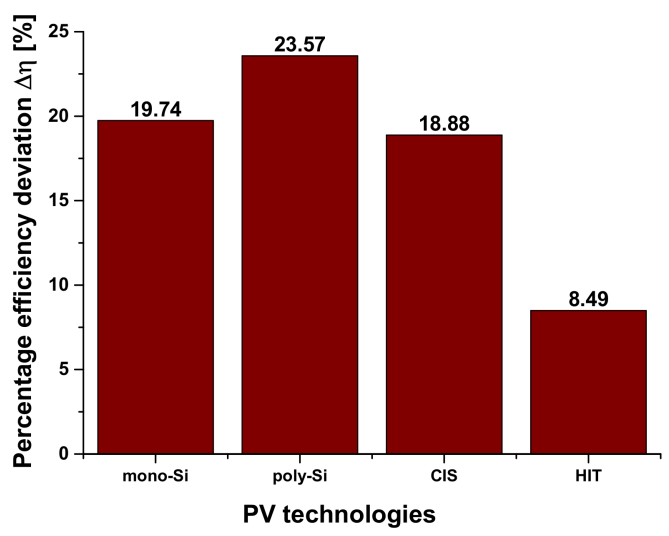

Figure 8. Percentage deviation in the energy efficiency for each PV module technology studied.

Figure 9 shows the monthly average ratio performance of the PV modules. It can be clearly observed in Figure 9 that the monthly average ratio performance varied between a minimum value of $84.22 \%$ in August and a maximum value of $96.56 \%$ in January for the HIT module. It varied between the minimum value of $76.35 \%$ in August and the maximum value of $85.15 \%$ in January for the CIS module. It varied between the maximum value of $87.85 \%$ in January and the lowest value of $71.07 \%$ in August for the mono-Si module. Finally, for the poly-Si module, it had the highest value of $81.64 \%$ in January and the lowest value of $71.11 \%$ in August. In addition, the ratio performance of the efficiency $\left(P R \_\eta\right)$ for all PV module technologies increased from September to March and then decreased afterward. The results obtained also show a seasonal variation of this parameter due to the solar spectrum response and the temperature variations. This observation was also reported by [30]. Indeed, the ratio performance analysis indicates that the performance of the PV modules depends on climatic parameters and the variations in environmental conditions [31].

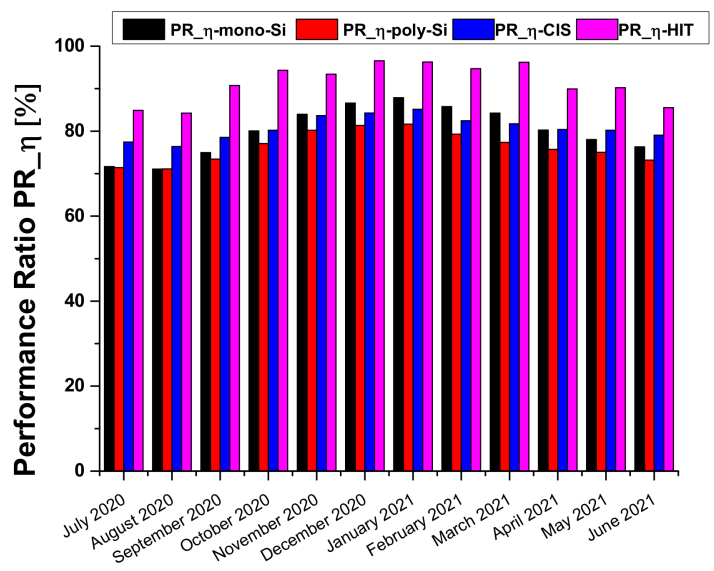

Figure 9. Monthly average ratio performance of energy efficiency for each PV module technology.

Figure 10 shows the minimum and maximum ratio performance (PR_H) of the four PV modules under investigation. It can be concluded that the gap between the PR_H of the different modules was small. In fact, the HIT module possessed the highest yearly PR_H (91.14\%), followed by the CIS module $(81.12 \%)$, the mono-Si module $(80.06 \%)$ and finally the poly-Si $(76.39 \%)$ module. It can be concluded that the values of the yearly PR_H of the PV modules during the monitoring period may be considered acceptable with respect to the values which were mentioned in the literature. It can be said that the results obtained on the radio performance in [23] and in the present study lead to the same conclusion concerning the technologies suitable for use in semi-arid and arid regions. 


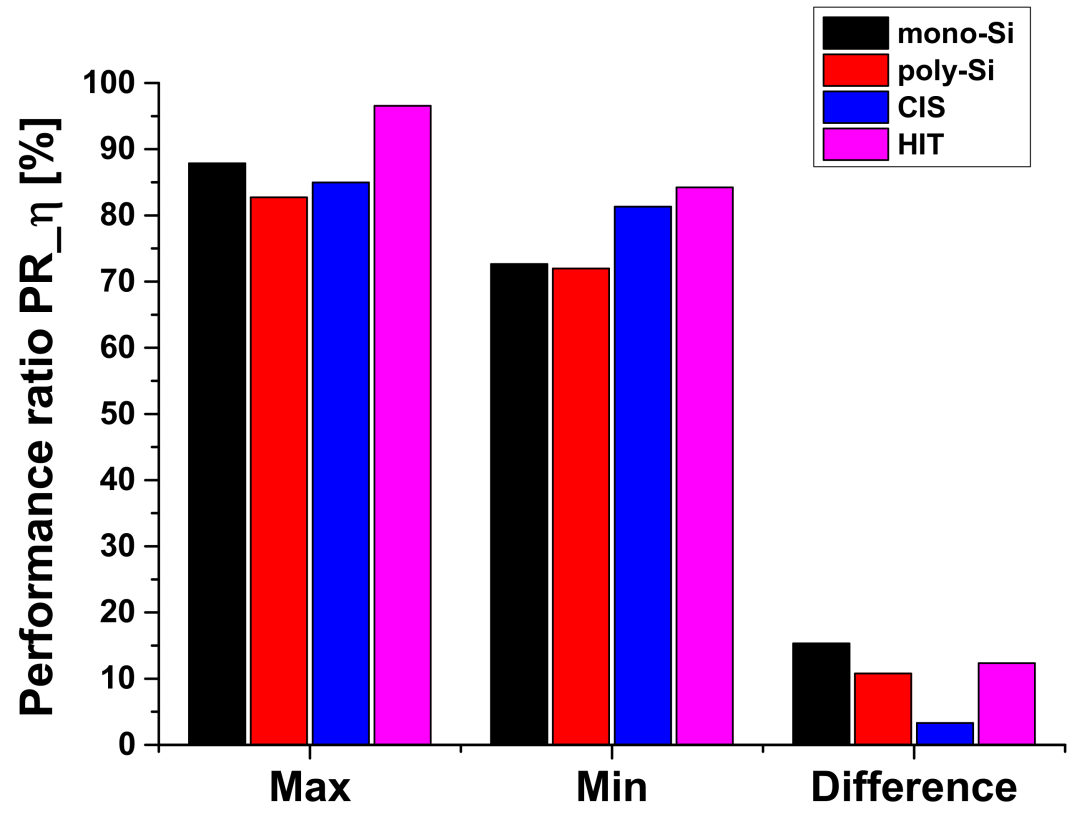

Figure 10. PR_ $\eta$ of the tested PV modules.

Figure 11 shows the curves of the monthly energy efficiency versus the air temperature for each PV module technology. It can be clearly observed that these curves have a linear behavior: the monthly energy efficiency decreased with the increase in the air temperature nearly in the same manner for all the PV module technologies studied in this paper. However, for the thin-film module technology, the temperature dependence on the real efficiency of the concerned module was weaker.

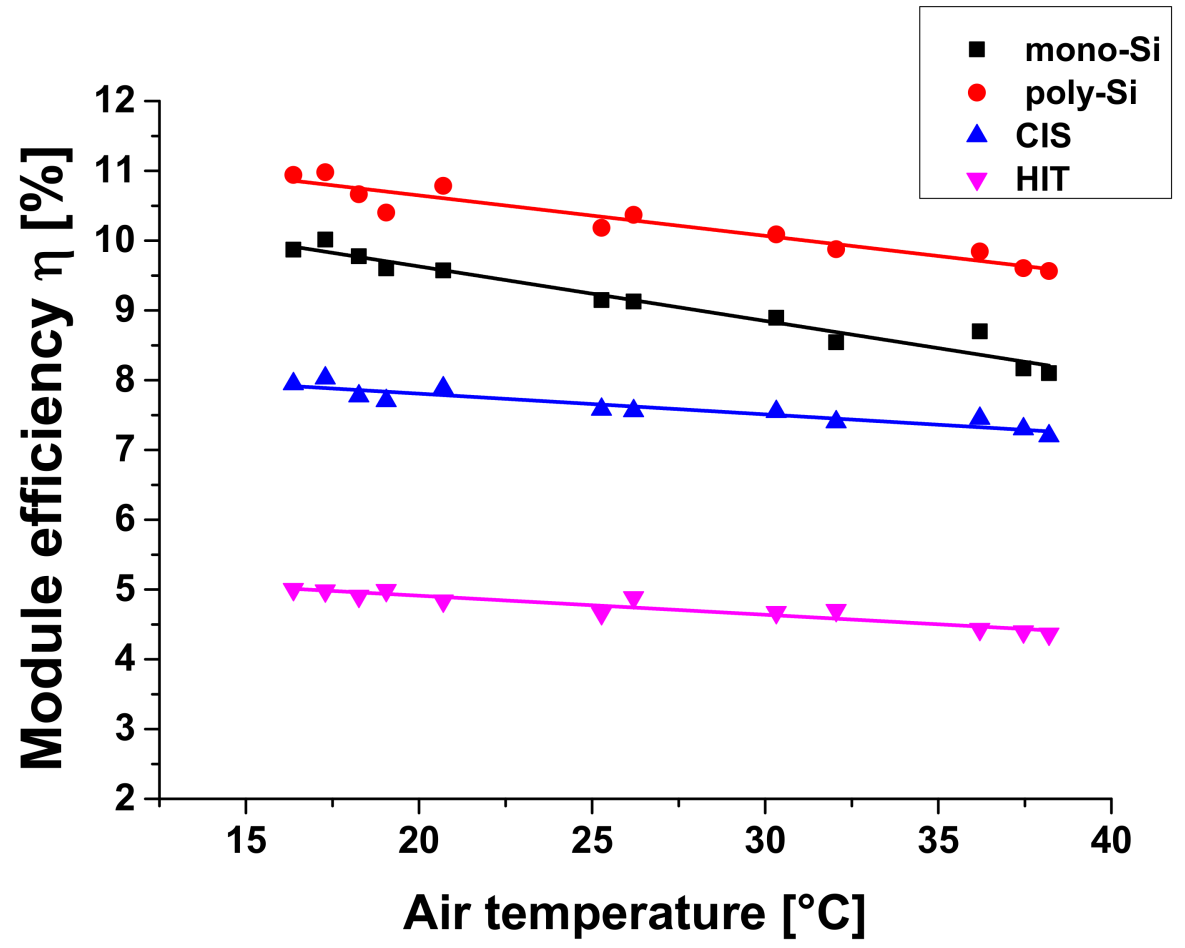

Figure 11. Relationship between monthly energy efficiency and air temperature for each PV module technology.

Table 3 summarizes the experimental average energy efficiency, percentage deviation and ratio performance for each PV module technology. It can be concluded that the PR_H of 
the HIT PV module was the highest compared to the CIS PV module, mono-Si PV module and poly-Si PV module throughout the whole year.

Table 3. Experimental average energy efficiency, percentage deviation and ratio performance for each PV module technology.

\begin{tabular}{|c|c|c|c|c|c|c|c|c|c|}
\hline \multirow{2}{*}{ PV Technology } & \multicolumn{3}{|c|}{ PV Efficiency (\%) } & \multicolumn{3}{|c|}{ Percentage Deviation $\Delta \eta(\%)$} & \multicolumn{3}{|c|}{ Ratio Performance $P R \_\eta(\%)$} \\
\hline & Min & Max & Av & Min & $\operatorname{Max}$ & Av & Min & Max & Av \\
\hline mono-Si & 8.10 & 10.01 & 9.13 & 12.15 & 28.93 & 19.74 & 71.07 & 87.85 & 80.06 \\
\hline poly-Si & 9.56 & 10.98 & 10.27 & 17.26 & 28.04 & 23.57 & 71.11 & 81.64 & 76.39 \\
\hline CIS & 7.20 & 8.03 & 7.65 & 14.85 & 23.65 & 18.88 & 76.35 & 85.15 & 81.12 \\
\hline HIT & 4.36 & 5.00 & 4.74 & 3.44 & 15.78 & 8.49 & 84.22 & 96.56 & 91.14 \\
\hline
\end{tabular}

Table 4 presents an updated summary of the performance indices for the most important investigations in the literature. 
Table 4. Performance parameters of PV modules and systems for different locations.

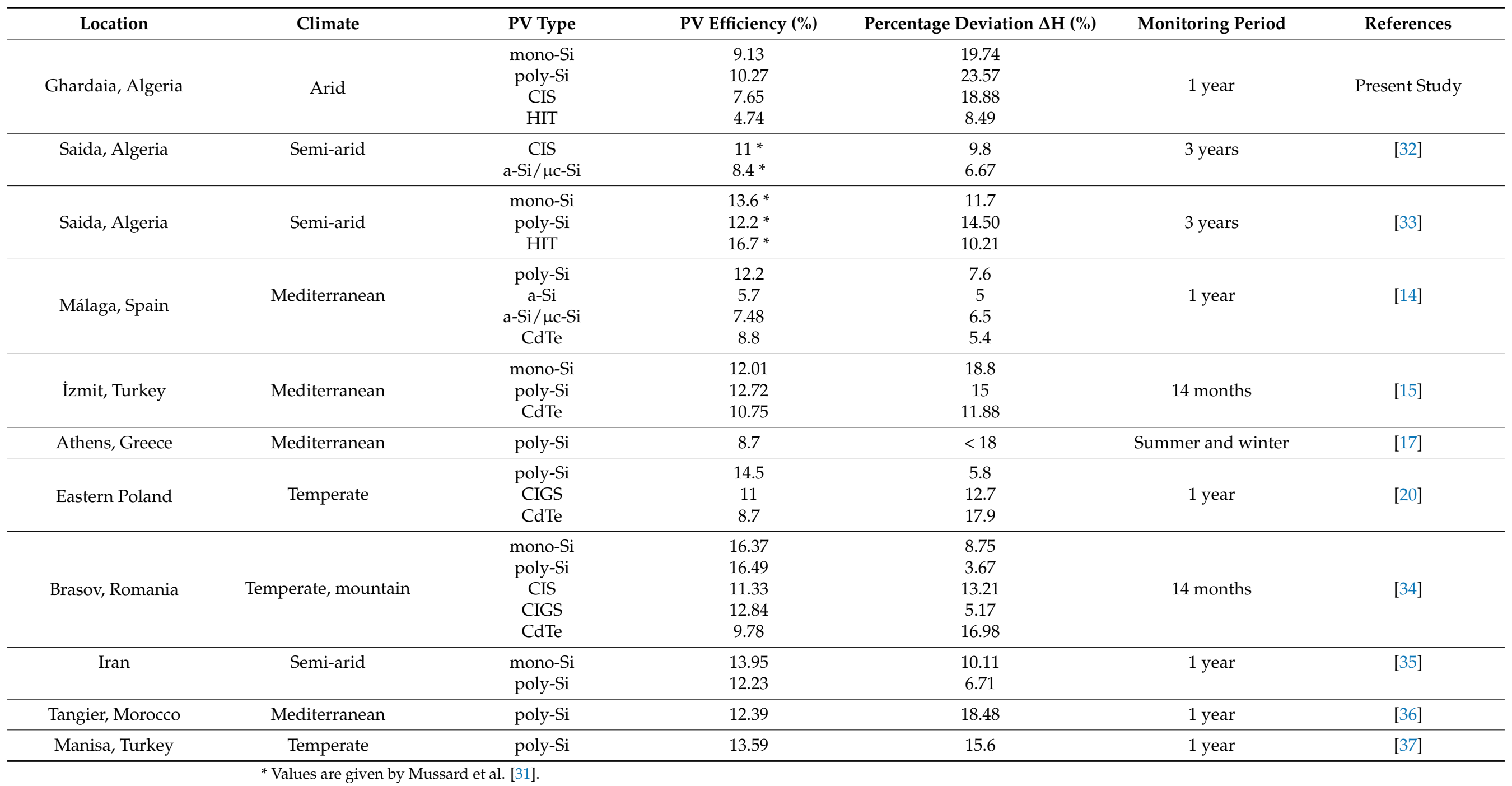




\section{Conclusions}

The main objective of this paper was to present a detailed investigation of the effect of the outdoor climatic conditions of the study site on the performance of different types of photovoltaic (PV) module technologies based on the measurements obtained onsite for the four different PV module technologies installed at URAER, which is characterized by an arid climate.

This study was based on monitoring the total electrical energy produced from each PV module technology under study after exposure to the outdoor climate during a period of 12 months according to the recommendations developed by the International Energy Agency (IEA). The present study led to the following conclusions:

- $\quad$ The average air temperature and daily average solar radiation measured from July 2020 to June 2021 in Ghardaïa were $26.45^{\circ} \mathrm{C}$ and $6.12 \mathrm{~kW} / \mathrm{m}^{2}$, respectively. Under these values, the average energy efficiency of the tested modules was $4.74 \%, 7.65 \%, 9.13 \%$ and $10.27 \%$ for the HIT (64 Wp), CIS (40 Wp), mono-Si (150 Wp) and poly-Si (125 Wp), respectively. These resulting efficiencies were much lower than the efficiencies of the same PV modules under STC as stipulated by the manufacturer, which were $5.18 \%, 9.43 \%, 11.4 \%$ and $13.45 \%$, respectively. In addition, the ratio performances of the tested modules were found to be $91.14 \%, 81.12 \%, 80.06 \%$ and $76.39 \%$ for the HIT, CIS, mono-Si and poly-Si modules, respectively. By contrast, the corresponding percentage deviations in energy efficiency calculated for the aforementioned modules were $8.49 \%, 18.88 \%, 19.74 \%$ and $23.57 \%$ for the HIT, CIS, mono-Si and poly-Si modules, respectively.

- $\quad$ The increases in module temperature resulted in decreases in energy efficiency for all the technologies tested. The influence of temperature on the poly-Si module was more predominant than on the thin layer.

- The PV module efficiencies and percentage deviations were compared with those obtained in other similar studies, as presented in Table 4, in order to validate the results and outcomes of the present study.

- The low variation in the efficiency of the HIT module shows that the operation of this type of module is better suited to the climatic conditions of the site of the present study.

- The results obtained on the data provided can be useful in forecasting the power generation and PV system design of different types of PV module technologies under operating conditions similar to those in the region studied. At the same time, the data can ensure optimally precise sizing of PV plants following specific energy demands.

Based on the analysis presented, it can be concluded that the thin-film photovoltaic technology can be very promising for large applications in regions characterized by arid climate. However, the required surface area plant of the thin-film module technology is higher than that for the crystalline-based panel, which may prove disadvantageous if there is no available area. This constraint can be solved by increasing efficiency. The average efficiency of the HIT is $21 \%$, and the manufacturing roadmap forecasts reaching $24 \%$ by $2030[38,39]$. In fact, the choice of a specific technology to be installed at a given site can be influenced by some other factors not taken into account in this work, such as windstorms, dust, degradation and cost. It would be important to focus on the evaluation of the degradation rate of each module technology in order to make the optimal decision on the technologies better adapted to the region studied.

Author Contributions: Conceptualization, A.F. and I.H.-M.; methodology, A.F., I.H.-M., L.Z., M.K., A.K. and S.D.; software, A.F., I.H.-M., L.Z. and M.K.; validation, A.F., A.K., S.D., A.K. and S.D.; formal analysis, A.F., A.K., S.D., A.K. and S.D.; investigation, A.F., I.H.-M., A.K. and S.D.; resources, A.F. and I.H.-M.; data curation, A.F.; writing-original draft preparation, A.F., A.K. and S.D.; writing-review and editing, A.F., A.K., S.D. and M.A.; visualization, A.F. and I.H.-M.; supervision, A.K., S.D., R.K. and M.A.; project administration, A.K., S.D., R.K. and M.A.; funding acquisition, R.K. and M.A. All authors have read and agreed to the published version of the manuscript. 
Funding: This project was financially supported by the Directorate General for Scientific Research and Technological Development of the Algerian Ministry of Higher Education and Scientific Research.

Institutional Review Board Statement: Not Applicable.

Informed Consent Statement: Not Applicable.

Data Availability Statement: Not Applicable.

Acknowledgments: This work was supported by the German Research Foundation (DFG) and the Technical University of Munich (TUM) through the Open Access Publishing Program.

Conflicts of Interest: The authors declare no conflict of interest.

\section{Abbreviations}

$\begin{array}{ll}\text { Nomenclature } \\ \text { URAER } & \text { Unit for Applied Research in Renewable Energy } \\ \text { CIS } & \text { Copper indium selenide } \\ \text { HIT } & \text { Hetero-junction with intrinsic thin-layer silicon } \\ \text { poly-Si } & \text { Polycrystalline silicon } \\ \text { mono-Si } & \text { Monocrystalline silicon } \\ \text { a-Si } & \text { Amorphous silicon } \\ \text { CdTe } & \text { Cadmium telluride } \\ \text { a-Si/ } \mu \text { C-Si } & \text { Microcrystalline silicon } \\ \text { STC } & \text { Standard Test Conditions } \\ \text { AM } & \text { Air mass } \\ \text { IEA } & \text { International Energy Agency } \\ \text { IEC } & \text { International Electrotechnical Commission } \\ \text { DC } & \text { Direct current } \\ E_{D C} & \text { Output energy of the PV module } \\ P_{m e s} & \text { Maximum power measured } \\ G & \text { Global solar radiation in-plane } \\ S & \text { Total area of the module } \\ P R \_H & \text { Ratio performance } \\ \text { Greek Symbols } \\ \tau & \text { The time step of measurements } \\ H_{\text {real }} & \text { The real efficiency PV Module } \\ H_{S T C} & \text { The standard nominal efficiency } \\ \Delta H & \text { The percentage deviation }\end{array}$

\section{References}

1. Program for Renewable Energy and Energy Efficiency; Ministry of Energy and Mines: March 2011. Available online: https: / / www.energy.gov.dz/ (accessed on 20 November 2021).

2. Ahmadi, M.H.; Ghazvini, M.; Sadeghzadeh, M.; Nazari, M.A.; Kumar, R.; Naeimi, A.; Ming, T. Solar power technology for electricity generation: A critical review. Energy Sci. Eng. 2018, 6, 340-361. [CrossRef]

3. Ustun, T.S.; Nakamura, Y.; Hashimoto, J.; Otani, K. Performance Analysis of PV Panels Based on Different Technologies after Two Years of Outdoor Exposure in Fukushima, Japan. Renew. Energy 2019, 136, 159-178. [CrossRef]

4. Kumar, M.; Kumar, A. Performance assessment and degradation analysis of solar photovoltaic technologies: A review. Renew. Sustain. Energy Rev. 2017, 78, 554-587. [CrossRef]

5. Fouad, M.M.; Shihata, L.A.; Morgan, E.I. An Integrated Review of Factors Influencing the Performance of Photovoltaic Panels. Renew. Sustain. Energy Rev. 2017, 80, 1499-1511. [CrossRef]

6. Khatibi, A.; Razi-Astaraei, F.; Ahmadi, M.H. Generation and combination of the solar cells: A current model review. Energy Sci. Eng. 2019, 7, 305-322. [CrossRef]

7. Burduhos, B.-G.; Visca, I.; Dut, A.; Neagoe, M. Analysis of the Conversion Efficiency of Five Types of Photovoltaic Modules During High Relative Humidity Time Periods. IEEE J. Photovolt. 2018, 8, 1716-1724. [CrossRef]

8. Gholami, A.; Ameri, M.; Zandi, M.; Ghoachani, R.G.; Eslami, S.; Pierfederici, S. Photovoltaic potential assessment and dust impacts on photovoltaic systems in Iran: Review paper. IEEE J. Photovolt. 2020, 10, 824-837. [CrossRef] 
9. Christabel, S.C.; Srinivasan, A.; Winston, D.P.; Kumar, B.P. Reconfiguration solution for extracting maximum power in the aged solar PV systems. J. Electr. Eng. 2016, 16, 440-446.

10. Mariano, J.R.L.; Lin, Y.-C.; Liao, M.; Ay, H. Analysis of Power Generation for Solar Photovoltaic Module with Various Internal Cell Spacing. Sustainability 2021, 13, 6364. [CrossRef]

11. Abdullah, G.; Nishimura, H. Techno-Economic Performance Analysis of a $40.1 \mathrm{kWp}$ Grid-Connected Photovoltaic (GCPV) System after Eight Years of Energy Generation: A Case Study for Tochigi, Japan. Sustainability 2021, 13, 7680. [CrossRef]

12. Carr, A.J.; Pryor, T.L. A comparison of the performance of different PV modules types in temperate climate. Sol. Energy 2004, 76, 285-294. [CrossRef]

13. Sharma, V.; Kumar, A.; Sastry, O.; Chandel, S. Performance assessment of different solar photovoltaic technologies under similar outdoor conditions. Energy 2013, 58, 511-518. [CrossRef]

14. Caňete, C.; Carretero, J.; Sidrach-de-cardona, M. Energy performance of different photovoltaic module technologies under outdoor conditions. Energy 2014, 65, 295-302. [CrossRef]

15. Başoğlu, M.E.; Kazdaloğlu, A.; Erfidan, T.; Bilgin, M.Z.; Çakir, B. Performance analyzes of different photovoltaic module technologies under İzmit, Kocaeli climatic conditions. Renew. Sustain. Energy Rev. 2015, 52, 357-365. [CrossRef]

16. Elibol, E.; Özmen, Ö.T.; Tutkun, N.; Köysal, O. Outdoor performance analysis of different PV panel types. Renew. Sustain. Energy Rev. 2017, 67, 651-661. [CrossRef]

17. Gaglia, A.G.; Lykoudis, S.; Argiriou, A.A.; Balaras, C.A.; Dialynas, E. Energy efficiency of PV panels under real outdoor conditions-An experimental assessment in Athens, Greece. Renew. Energy 2017, 101, 236-243. [CrossRef]

18. Tahri, F.; Tahri, A.; Oozeki, T. Performance evaluation of grid-connected photovoltaic systems based on two photovoltaic module technologies under tropical climate conditions. Energy Convers. Manag. 2018, 165, 244-252. [CrossRef]

19. Kafui, A.D.; Seres, I.; Farkas, I. Efficiency Comparison of Different Photovoltaic Modules. Acta Technol. Agric. 2019, $22,5-11$. [CrossRef]

20. Gulkowski, S.; Zdyb, A.; Dragan, P. Experimental efficiency analysis of a photovoltaic system with different module technologies under temperate climate conditions. Appl. Sci. 2019, 9, 141. [CrossRef]

21. Adouane, M.; Al-Qattan, A.; Alabdulrazzaq, B.; Fakhraldeen, A. Comparative performance evaluation of different photovoltaic modules technologies under Kuwait harsh climatic conditions. Energy Rep. 2020, 6, 2689-2696. [CrossRef]

22. Guenounou, A.; Malek, A.; Aillerie, M. Comparative performance of PV panels of different technologies over one year of exposure: Application to a coastal Mediterranean region of Algeria. Energy Convers. Manag. 2016, 114, 356-363. [CrossRef]

23. Balaska, A.; Tahri, A.; Tahri, F.; Stambouli, A.B. Performance assessment of five different photovoltaic module technologies under outdoor conditions in Algeria. Renew. Energy 2017, 107, 53-60. [CrossRef]

24. Chikha, M.; Berkane, S.; Mahrane, A.; Sellami, R.; Noureddine Yassaa, N. Performance assessment of a 400 kW $\mathrm{p}_{\mathrm{p}}$ multi-technology photovoltaic grid-connected pilot plant in arid region of Algeria. Renew. Energy 2021, 172, 488-501. [CrossRef]

25. Fezzani, A.; Hadj-Mahamed, I.; Drid, S.; Zaghba, L.; Bouchakour, A.; Benbitour, M. Degradation and performance evaluation of PV module in desert climate conditions with estimate uncertainty in measuring. Serb. J. Electr. Eng. 2017, 14, 277-299. [CrossRef]

26. Photovoltaic System Performance Monitoring-Guidelines for Measurement, Data Exchange and Analysis. Technical Committee GEL/82; BS EN 61724:1998; B.E. British Standards Institution: London, UK, 1998.

27. Marion, B.; Adelstein, J.; Boyle, K.; Hayden, H.; Hammond, B.; Fletcher, T.; Canada, B.; Narang, D.; Shugar, D.; Wenger, H.; et al. Performance Parameters for grid-connected PV systems. Energy Rep. 2005, 3, 76-84 Record of the thirty.

28. Ayompe, L.M.; Duffy, A.; Mccormack, S.J.; Conlon, M. Measured performance of a $1.72 \mathrm{~kW}$ rooftop grid connected photovoltaic system in Ireland. Energy Convers. Manag. 2011, 52, 816-825. [CrossRef]

29. Sharma, R.; Goel, S. Performance analysis of a $11.2 \mathrm{~kW}_{\mathrm{p}}$ roof top grid-connected PV system in Eastern India. Energy Rep. 2017, 3, 76-84. [CrossRef]

30. Singh, R.; Sharma, M.; Rawat, R.; Banerjee, C. Field Analysis of three different silicon-based Technologies in Composite Climate Condition-Part II-Seasonal assessment and performance degradation rates using statistical tools. Renew. Energy 2020, 147, 2102-2117. [CrossRef]

31. Mussard, M.; Amara, M. Performance of solar photovoltaic modules under arid climatic conditions: A review. Sol. Energy 2018, 174, 409-421. [CrossRef]

32. Tahri, A.; Silvestre, S.; Tahri, F.; Benlebna, S.; Chouder, A. Analysis of thin film photovoltaic modules under outdoor long term exposure in semi-arid climate conditions. Sol. Energy 2017, 157, 587-595. [CrossRef]

33. Silvestre, S.; Tahri, A.; Tahri, F.; Benlebna, S.; Chouder, A. Evaluation of the performance and degradation of crystalline silicon-based photovoltaic modules in the Saharan environment. Energy 2018, 152, 57-63. [CrossRef]

34. Visa, I.; Burduhos, B.; Neagoe, M.; Moldovan, M.; Duta, A. Comparative analysis of the infield response of five types of photovoltaic modules. Renew. Energy 2016, 95, 178-190. [CrossRef]

35. Mirzaei, M.; Mohiabadi, M.Z. A comparative analysis of long-term field test of monocrystalline and polycrystalline PV power generation in semi-arid climate conditions. Renew. Sustain. Dev. 2017, 38, 93-101. [CrossRef]

36. Attari, K.; Elyaakoubi, A.; Asselman, A. Performance analysis and investigation of a grid-connected photovoltaic installation in Morocco. Energy Rep. 2016, 2, 261-266. [CrossRef]

37. Murat Ates, A.; Singh, H. Rooftop solar Photovoltaic (PV) plant-One year measured performance and simulations. J. King Saud Univ. Sci. 2021, 33, 101361. [CrossRef] 
38. International Technology Roadmap for Photovoltaic (ITRPV). 11th Ed. Results. 2019. Available online: https://itrpv.vdma.org/ documents/27094228/29066965/ITRPV\%302020.pdf/ba3da187-3186-83de-784e-6e3b10d96f3f (accessed on 20 November 2021).

39. Victoria, M.; Haegel, N.; Peters, I.M.; Sinton, R.; Jäger-Waldau, A.; del Cañizo, C.; Breyer, C.; Stocks, M.; Blakers, A.; Kaizuka, I.; et al. Solar photovoltaics is ready to power a sustainable future. Joule 2020, 5, 1041-1056. [CrossRef] 